various CHDs and similarly between hairdresser work and oral clefts. Future research could aim to identify potential workplace reproductive hazards and interventions in these occupations.

\section{0-147 SENSITIZATION AND DERMATITIS AMONG EPOXY EXPOSED LAMINATION WORKERS PRODUCING WIND TURBINE BLADES}

${ }^{1}$ Alexandra Golabek Christiansen, Ole Carstensen, Henrik Albert Kolstad, Jakob Hjort Bønløkke, Per Axel Clausen, Marléne Isaksson, Mette Sommerlund, Vivi Schlünssen. ${ }^{1}$ Aarhus University Hospital, Denmark

10.1136/OEM-2021-EPI.146

Introduction Epoxy resin systems (ERS) are well-known sensitizers of the skin. A high prevalence of sensitization and dermatitis has been reported among workers exposed to ERS. Due to this, comprehensive personal protective equipment is required when working with ERS. No recent studies have evaluated the effect of the use of such safety equipment.

Objectives The aim of this study was to estimate the occurrence of dermatitis and sensitization to ERS among epoxyexposed workers producing wind turbine blades in Denmark while using up-to-date protective measures.

Material and Methods A cross-sectional study was performed at two Danish factories producing rotor blades for wind turbines. A screening questionnaire regarding recent and former skin rashes, allergies, atopic dermatitis, and asthma was answered by 181 epoxy-exposed production workers and 41 non-exposed office workers. Physical examination of the skin was followed by testing with a tailored patch test series based on toxicological assessments of possible sensitizing chemicals in the work materials including epoxy resins and hardeners as well as 35 allergens from the European Standard Series (TRUE test). Atopy was defined as elevated serum levels of $\operatorname{IgE}$ for standard inhalation allergens.

Results In total, 16 (8.8\%) of the exposed workers were sensitized to one or more epoxy compounds, whereas none of the non-exposed office workers were sensitized. Non-atopic participants exposed to epoxy products showed an increased odds ratio $(\mathrm{OR}=2.02$; CI $0.56-7.34)$ of dermatitis while the opposite was seen for atopic participants $(\mathrm{OR}=0.08$; CI $0.02-0.4)$. A 4-fold increased odds ratio $(\mathrm{OR}=4.5$; CI 1.57-13.13) of dermatitis was observed among workers sensitized to epoxy resins. Atopy was not associated with epoxy sensitization $(\mathrm{OR}=0.73$, CI $0.22-2.42)$.

Conclusion Despite up-to date skin protection dermatitis and sensitization to ERS remain high among epoxy exposed lamination workers. These findings document the need for new and efficient preventive efforts.

\section{0-217 ASBEST CHRYSOTILE COHORT STUDY PROFILE, EXPOSURE DISTRIBUTION AND OUTCOMES}

${ }^{1}$ Ann Olsson, Joachim Schuz, Kurt Straif, Hans Kromhout, Monika Moissonnier, Evgenia Ostroumova, Graham Byrnes, Gilles Ferro, Eleonora Feletto, Sara J Schonfeld, Igor Bukhtiyarov, Iraklii Tskhomariia, Sergey Kashanskiy, Tatiana Morozova, Evgeny Kovalevskiy. 'International Agency for Research on Cancer, France

\subsection{6/OEM-2021-EPI.147}

Introduction A historical cohort study in workers occupationally exposed to chrysotile was set up in the town of Asbest, the Russian Federation, to study their cause-specific mortality, with a focus on cancer.

Objective Describe the Asbest Chrysotile Cohort established in 2013.

Methods Cohort enrolment was based on employment records from JSC Uralasbest chrysotile mine and processing factories. Exposure assessment was based on detailed occupational histories extracted from company archives and personal workbooks linked to $>90,000$ measurements, and conversion factors derived using a subset of parallel dust/fibre measurements. This resulted in yearly dust and fibre estimates for each employed calendar year. Vital status was ascertained from multiple sources including company records, the Pension Fund, the Federal Migration Service, and Civil Act Registration Office providing the date and cause of death of those deceased in Sverdlovsk Region.

Results The cohort comprises 22,463 men and 13,374 women working $\geq 1$ year between $01 / 01 / 1975$ and $31 / 12 / 2010$ in JSC Uralasbest and followed until 31/12/2015. Cumulative exposure of exposed women was higher than for men $(49 \mathrm{mg} / \mathrm{m} 3$ dust years and 33 fibres $/ \mathrm{cm} 3$ years vs. $31 \mathrm{mg} / \mathrm{m} 3$ dust years and 19 fibres/cm3years). At the end of follow-up, 52\% of the cohort was alive, $36 \%$ deceased, and 12\% censored at last date known to be alive in the Sverdlovsk Region. For those who died the mean age at death was 59.4 years for men and 66.5 for women. The most frequent underlying cause of death for all was circulatory diseases, followed by external causes and cancer in men, and cancer and external causes in women. Cancer mortality was dominated by lung cancer in men and breast cancer in women.

Conclusion The cohort is unique in its size, long follow-up, and substantial proportion of female workers. The cohort is relatively young, and the mortality patterns follow those of the Russian population. Risk analyses are underway.

\section{0-231 HEALTH, LIFESTYLE AND OCCUPATIONAL RISKS IN 10,931 INFORMATION TECHNOLOGY WORKERS}

Jim Lewsey, Srinivasa Vittal Katikireddi, Ewan Macdonald, Evangelia Demou, ${ }^{1}$ Drushca Lalloo. 'University of Glasgow, United Kingdom

\subsection{6/OEM-2021-EPI.148}

Introduction Informational technology (IT) and the IT workforce are rapidly expanding with potential occupational health implications. Yet to date, IT worker health is under-studied and large-scale studies are lacking.

Objectives To investigate health, lifestyle and occupational risk factors of IT workers.

Methods We evaluated self-reported health, lifestyle and occupational risk factors for IT workers in the UK Biobank database. Using logistic regression, we investigated differences between IT workers and all other employed participants. Regression models were repeated for IT worker sub-groups (managers, professionals, technicians) and their respective counterparts within the same Standard Occupational Classification (SOC) major group (functional managers, science and technology professionals, science and technology associate professionals).

Results Overall, 10,931 (4\%) employed participants were IT workers. Compared to all other employed participants, IT workers reported similar overall health, but lower lifestyle risk factors for smoking and obesity. Sedentary work was a 